\title{
Voces y cuerpos femeninos: educación y resistencia en el cine argentino
}

\section{Corpos e vozes femininas: educação e resistência no cinema argentino}

\section{Feminine bodies and voices: education and resistance in Argentine cinema}

\author{
Natacha Muriel López Gallucci*
}

\begin{abstract}
RESUMEN
La historia audiovisual de las mujeres en Argentina coloca en perspectiva los marcadores formales, temáticos y estilísticos tras la performance; su visión de la realidad, los usos del cuerpo y los procesos de autopoiesis, enfatizan procesos estéticos subjetivos que trascienden a lo social a través de la mediatización acústica y visual. Ciertamente, las historias del teatro, la radio y del cine argentino no han otorgado la merecida atención a estos procesos formativos artísticos y de educación del cuerpo dentro del contexto de la historia de las mujeres. El cuerpo en la representación fílmica presenta un aspecto histórico poco estudiado, que forma parte de una estética de resistencia de género socio cultural. Son esos procesos los que resignifican toda nuestra comprensión acerca de las políticas de representación en Argentina, de lo visible y de lo audible en las primeras tres décadas del siglo XX.

Palabras clave: Educación del cuerpo. Voz. Mujeres. Resistencia. Cine argentino.
\end{abstract}

\section{RESUMO}

A história audiovisual das mulheres na Argentina coloca em perspectiva os marcadores formais, temáticos e estilísticos por trás da performance. A

* Universidade Federal do Cariri (UFCA). Instituto Interdisciplinar de Sociedade, Cultura e Arte (IISCA). Cariri, Ceará, Brasil. E-mail: natacha_muriel@hotmail.com. https://orcid.org/00000001-8085-4177. 
visão da realidade, os usos do corpo e os processos de autopoiesis enfatizam processos estéticos subjetivos que transcendem ao plano social através da midiatização acústica e visual. Certamente, as histórias do teatro, do rádio e do cinema argentino não têm outorgado a merecida atenção a esses processos formativos artísticos e de educação do corpo dentro do contexto da história das mulheres. $\mathrm{O}$ corpo, na representação fílmica, apresenta um aspecto histórico pouco estudado, que forma parte de uma estética de resistência de gênero sociocultural. São esses processos os que resignificam toda nossa compreensão acerca das políticas de representação na Argentina, do visível e do audível nas primeiras três décadas do século XX.

Palavras-chave: Educação do corpo. Voz. Mulheres. Resistência. Cinema argentino.

\begin{abstract}
The audiovisual history of women in Argentina puts in perspective the formal, thematic and stylistic markers behind the performance. Their vision of reality, the uses of the body and the processes of autopoiesis emphasize subjective aesthetic processes that transcend the social through acoustic and visual mediatization. Certainly, the history of theater, radio and Argentine cinema has not given the deserved attention to these artistic training processes and body education within the context of the history of women. The body in the filmic representation presents a little-studied historical aspect, which is part of an aesthetics of socio-cultural gender resistance. These processes resignify all our understanding of the politics of representation in Argentina, of the visible and the audible in the first three decades of the 20th century.

Keywords: Education of the body. Voice. Women. Resistance. Argentine cinema.
\end{abstract}

\title{
Historia de las mujeres en Argentina
}

Las primeras manifestaciones de interés en torno a la historia de las mujeres en la Argentina datan de la década de 1970. Estas contribuciones historiográficas tuvieron el claro objetivo de recuperar a las mujeres que cruzaron, con disímiles destinos, el umbral de lo doméstico para ocupar esferas púbicas. Trabajos tributarios de diversas tradiciones historiográficas y políticas destacaron el protagonismo femenino revelando detalles del accionar y formas de pensar, como fueron los textos pioneros de Lily Sosa de Newton en su 
Diccionario biográfico de mujeres argentinas (1972), El movimiento feminista argentino en la década de 1970 de Nancy Caro Hollander (1974), El trabajo de la mujer en la Argentina de Catalina Wainermann y Marysa Navarro (1979) y más tarde, el libro Las feministas de María del Carmen Feijóo (1980). Pero el creciente interés en abordar la historia de las mujeres delineó senderos que luego tomaron inúmeras bifurcaciones. Al experimentar formatos alternativos a la biografía que, a pesar de ser un discurso recurrente, presenta cierta visión elitista y parcial, la llamada historia contributiva buscó destacar acciones significativas y efectivas conquistas de las mujeres, como el sufragio, el trabajo, la educación y la literatura. Sin una verdadera superación crítica del modelo androcéntrico, las prácticas de la escritura histórica contributiva presentaron, no obstante, aspectos claves de las diferencias de accionar y pensar de varones y mujeres como complementariedades (GIL LOZANO; PITA; INI, 2000, p. 8).

En el momento en que comienza a esbozarse el final de la dictadura militar en Argentina, tópicos como el de la historia de la vida cotidiana, asimilaron los trayectos de la Escuela francesa de los Annales creada por Lucien Febvre y Marc Bloch (1929) y asumieron la cuestión del género como una categoría analítica que observamos, hasta ese momento, no había sido central. No obstante, esta categoría se instala holgadamente en la nueva coyuntura organizando gran parte de las investigaciones historiográficas (BARRANCO, 2004-2005, p. 54). Los estudios de la vida privada en Argentina habían redescubierto a las mujeres en el ámbito de lo hogareño (gineceo), presentaban a la mujer aún ritmada por lo biológico, con relación a sus vestuarios, comidas y rituales, pero dejaban un poco de lado el campo de incidencia pública. La nueva perspectiva de género, producto de la transformación de la categoría de sexo, le dio visibilidad a aspectos que no habían ganado ninguna atención hasta ese momento, historiando y consolidando un ámbito de estudio que, más allá de lo biológico, buscaba comprender los deseos, las ideas y acciones de las mujeres en cuestiones políticas, educativas, morales, estéticas y culturales.

En la década de 1980, con la efectiva retomada de la democracia en el país, son adoptados los principios epistémicos consagrados por la historiografía social y, llegada la década de 1990, se destaca la inclusión del psicoanálisis y del pensamiento de Michel Foucault en las investigaciones históricas. Según Dora Barranco, la recepción de la Historia Social y Cultural, las teorías de Michel Foucault, Jacques Lacan, Raymond Williams y otros, comenzaron a resonar y cruzarse sin incomodar; pues era más importante dialogar con un nuevo corpus epistémico que fundamentase el crucial desplazamiento del concepto de Sujeto de las tradiciones "modernas" para una reelaboración que renovase la disciplina histórica (BARRANCO, 2004-2005, p. 52). Se produce así el descentramiento necesario para profundizar los estudios sobre las mujeres a la luz de las estruc- 
turas psíquicas, las relaciones de poder y de los dispositivos como formas de producción de la subjetividad en cada momento histórico. Con la influencia del feminismo en la Argentina se establecen tres ejes temáticos alineados a los estudios de las mujeres, i) en relación con la sujeción y el cautiverio, ii) alrededor de sus resistencias y luchas y iii) en relación con al cuerpo, en procesos de desapropiación, apropiación y educación del cuerpo.

Enfatizando este último aspecto buscamos transitar las posibles relaciones entre las mujeres argentinas y el cine de las primeras décadas del siglo XX, asumiendo que el discurso audiovisual ha sido uno de los ámbitos por excelencia de la educación gestual del cuerpo. La educación moralizante y normativa es un elemento preexistente en el país que disputó casi todos los ámbitos artísticos hasta el momento que se detectan signos de resistencias, luchas y conquistas de ciertas mujeres iniciadas en la apropiación artística de sus cuerpos. Según Soares, la educación del cuerpo puede ser comprendida como una noción abarcadora; dicha noción remite a relaciones entre la asunción del cuerpo y la posibilidad de su educación más allá de la escuela o las academias de arte; en sentido amplio se trata de cómo operan en cada sociedad las denominadas prácticas educativas, imprimiendo las marcas de la cultura, las conductas y los comportamientos tanto privados como públicos; y en el caso de las técnicas corpóreo vocales que nos interesa destacar, como su transmisión permite exponer aspectos claves de las sensibilidades socioculturales emergentes (SOARES, 2014, p. 219).

Llama la atención lo tardío que surgen las investigaciones teóricas sobre el cuerpo en la historia audiovisual argentina; a pesar de que ese fue un momento de emergencia de nuevas representaciones corporales a nivel mundial signado por la fotografía y el cine. En el ámbito del primer cine, antes de adoptar un formato hegemónico codificado por la industria norteamericana, las mujeres ya intervenían como actrices dramáticas, compositoras, bailarinas, músicos y también productoras. Espacios que la teoría crítica feminista trata de reconstruir debido a que, sintomáticamente, la historiografía ha esquivado esos procesos de resistencia, destacando apenas los estereotipos de los deseos femeninos presentados por el clasicismo cinematográfico. Se ha estudiado con mayor profundidad la emergencia de las clases populares, los caracteres de las artes de masa y el nacimiento de la industria cinematografía. Sin embargo, existe un escueto material sobre la visión de las mujeres y la experimentación artística y corporal que formó parte del mismo proceso. El trabajo femenino se encuentra separado de las historias de la industria cinematográfica que se benefició, justamente, de estos nuevos productos culturales creados por mujeres. Muchas de las actrices, productoras, cantantes y bailarinas fueron mal vistas en sus primeras incursiones hasta alcanzar el reconocimiento nacional o internacional, fundamentalmente 
por aquellos que identificaban el arte a los cánones de la formación tradicional como era la de tradición española o criollista ${ }^{1}$.

\section{La educación del cuerpo}

Es importante destacar el ocultamiento del papel de las mujeres en ese proceso histórico argentino signado tan fuertemente por la alteridad, producto de la inmigración, la modernización y la tecnología. Es necesario considerar la manera en que establecieron lazos de convivencia laborales y educativas en ese momento de crisis social en el país; desde la diferencia de clase, de saberes, de etnia y, fundamentalmente, desde la diferencia de género. Los hogares argentinos, como es sabido, cambiaron profundamente a partir de la paulatina llegada del fonógrafo (1878), así como también cambió el espacio público cuando llega el cinematógrafo (1896). Inclusive se puede observar que, entrados los años de 1920, surge la radiofonía (y también, hacia los años de 1930 el formato del radioteatro), tecnologías éstas que demandaron con urgencia la adquisición de saberes, técnicas y usos codificados del cuerpo y la voz, abriendo un espacio de praxis artística y social para las mujeres. La escasez laboral también condicionó esa necesidad de educación corporal no académica; se amplió el terreno del aprendizaje del arte escénica, de las elites a las clases emergentes y se trasladó a las mujeres que deseaban ser artistas, del ámbito del entretenimiento hogareño o del conservatorio, para el ambiente público y popular.

En las primeras tres décadas del siglo XX, las mujeres que no pertenecían a las clases altas y que deseaban aprender artes y otros métier para ganarse la vida debían atravesar espacios de tensión y desconfianza como eran el cabaret,

1 En la Argentina se registra una fuerte asociación entre la dominación hispánica y la producción artística en el teatro, la música y la danza, principalmente vinculada a función evangelizadora y didáctica de la campaña jesuítica hasta 1767. Posteriormente a la expulsión de los padres jesuitas y hasta la mitad del siglo XIX, se destaca entre las elites la enseñanza y la práctica regular de las Danzas Clásicas españolas de la Escuela Bolera. La elite en Buenos Aires no se mezcla ni con las tradiciones rurales ni con la cultura africana que se expande en todo el Rio de La Plata. Diversas companias europeas llegan a Buenos Aires entre ellas los ballets napoleónicos, las companias francesas, la Comapania Coreografica italiana (1883) con gran éxito. Entre 1913 y 1917, los Ballets Russes de Diaghilev con Nijinsky, etc. Incorporando en la Argentina la estética del ballet moderno de Michel Fokin, El fauno de Nijinsky y los primeros ballets de Massine transformaron la percepción estética de la elite cultural. En 1916 baila Isadora Duncan e inumeras veces Anna Pavlova, entre 1917 y 1928. Nace así el Cuerpo de Baile del teatro Colón que estrenó su primer espectáculo El Gallo de oro de Rimsky-Korsakov en 1925 (FUMAGALLI, 2014). 
el circo o las revistas teatrales; se trató de un aprendizaje in situ. En este nuevo mundo de representación, la entrada en la radio y el proceso de adaptación del cine silente al sonoro produjeron una crisis en la Argentina y en el mundo. La voz y las técnicas corporales debieron ser educadas; la performance teatral, la danza y la canción entre las mujeres fue fruto de una verdadera tecnología de género (DE LAURETIS, 1987, p. 131) adoptando, en principio, matrices simples por imitación que fueron complejizándose. Se inicia así un proceso, de reconocimiento corporal acústico, visual y propioceptivo (no libre de resistencias) asociado a espacios subjetivos y colectivos de creación otorgados por los hombres más por necesidad que por derecho. Y así, las artistas fueron abriendo allí caminos, dentro del formato tradicional o moral religioso masculinizado que regía el orden social y de producción cultural como un todo. En las tres primeras décadas del siglo se consolidaron ámbitos de expresión en el circo, el teatro, la literatura, la danza, el cine y la radio. Estos dos últimos, se constituyeron hasta consolidarse como territorios mediatizados cada vez más masivos de exposición del cuerpo y de la voz. La radio y el cine constituyeron nuevas pautas y estrategias de creación importantes para la industria, pero también para la resistencia y legitimación de las identidades de género dentro de un contexto de clase. Y como alternativa a la prensa porteña, que registraba a las clases altas, la cultura de masa desde el cine y la radio transmitió valores asociados a los sectores más populares.

Considerando los estudios integrados de las historias de la radio, el cine y la música popular (tango, jazz y folclore) realizados por Matt Karush, observamos los vínculos y transformaciones que trajeron esas nuevas tecnologías, fundamentalmente en la Argentina de entre guerra, expresando una amplia división de clase. El autor cuestiona los paradigmas dominantes de la historiografía argentina que sostienen la idea de que, después de 1920, habría una disolución de las identidades de clase propiciando la integración de la población y la aparición de una cultura cívica sin antagonismos. Contrario a esa visión, Karush adjudica a las diferencias de clase un lugar central para pensar las tensiones de la nueva cultura de masa. Su tesis afirma que la cultura de masa en Argentina no contribuyó a gestar la unificación nacional, como en otros países, sino que generó polarización y recolocó en la escena cultural la hostilidad de las clases populares contra los ricos. (KARUSH, 2013, p. 18) Esa situación de hostilidad contra las elites reflejadas en la radio, el cine y la música, explica, se debió a la situación periférica en la que operaban los directores, músicos, empresarios y productores locales. Karush remite también a la existencia de una cultura popular previa que ya tenía características semejantes en el país. Frente a este panorama, el deseo de bienestar de los sectores populares convive en un clasismo integrador del clivaje social; y a pesar de hostil, esos sectores no rechazan el 
modelo capitalista, presentando apenas grupos afiliados a la izquierda obrera o al anarquismo. La cultura de masa difunde mensajes y fantasías ligados al ascenso social, intensifica las divisiones de clase creando y reproduciendo imágenes polarizantes; representaciones de un binarismo ético, entre el mundo de los pobres y trabajadores, de un lado, organizados en un ethos de solidaridad y autenticidad nacional; y del otro, las clases altas, territorio de lo inmoral, de visión individualista y egoísta, que estaría siempre intentando implantar los intereses extranjeros en el país.

En ese contexto, la industria cultural argentina también enfrentó entre 1920 y 1945 una competencia desigual con el Jazz y las películas norteamericanas. Los productores locales encontraron, en tópicos de la autenticidad nacional, elementos que les permitieron disputar la audiencia. La cinematografía, para reconstruir esa autenticidad nacional, retomó elementos de la cultura popular previa a 1920, como era el sainete, el discurso criollista, el maquinismo y el tango; reintroducidos como modelos de lo autóctono en la nueva cultura de masa, pero bajo el signo del melodrama. La Argentina, como otros países latinoamericanos, desarrolla una relación ambigua entre las tradiciones y el proyecto modernizador. La ideología nacionalista entendida como un fenómeno moderno, se articula íntimamente con lo tradicional, ese pasado rural idealizado (ARCHETTI, 2003, p. 9-10). Las producciones locales recurren a los valores de las literaturas fundadoras como Civilización y barbarie (1945) de Domingo F. Sarmiento y el poema Martin Fierro (1872) de José Hernández, así como a la iconografía construida por la Sociedad Fotográfica Argentina de Aficionados (1889). La iconografía criollista había retratado hombres y mujeres en el ámbito rural antes de la llegada del cinematógrafo. La colección Escenas del campo argentino (1885-1900) de Francisco Ayersa (1968) presenta ese espíritu neutralizador a través de imágenes sin conflicto de clase, de etnia o de género ${ }^{2}$. El discurso audiovisual argentino tomo muchas de las temáticas, encuadres, vestuarios y puntos de vista de los fotógrafos de la Sociedad. Sin embargo, esa retomada se dio bajo un espíritu de críticas y mucho más comprometido con las clases populares ${ }^{3}$. La tensión se

2 Los gauchos forman parte de mise en scènes junto a la guitarra, frente a la tapera, andando a caballo, rodeando con asombro el organito y su música, o aceptando el mate que le ofrece una "china" (mujer campesina). Las mujeres también exclusivamente blancas, de largas polleras, acompañan el descanso de los gauchos, conversan o son cortejadas por ellos. El encuadre panorámico del ambiente destaca la pureza de los hombres frente al tenor agreste y sobre el horizonte extenso del fondo pampeano. La mitificación del gaucho fue una forma de aceptación tejida por la Generacion de 1880 y aceptada por la sociedad porteña que aprovecho la imagen del gaucho frente a otra nueva alteridad, producto del avance y los desequilibrios traídos por la inmigración.

3 Por ejemplo en filmes como Nobleza gaúcha (GUNCHE; DE LA PERA, 1915); Juan sin ropa (BENOIT; QUIROGA, 1919), entre otros. 
evidencia entre un discurso positivista instalado en el cine de actualidades, que exalta el progreso, y el discurso nacionalista en películas de ficción histórica que irrumpen para las fiestas del Centenario de la revolución de mayo fundando un formato de tradición más argumental (CUARTEROLO, 2006, p. 125). Desde el cine silente hasta la llegada del sonoro y posterior creación de los grandes Estudios en Buenos Aires, es inevitable hacer referencia al lenguaje corpóreo vocal del tango, así como a sus temáticas recurrentes, aunque no excluyentes. El tango fue eje del modelo de representación del drama social urbano que se impone en la cinematografía a partir de 1930. El cine crea un lugar irrefutable de experimentación corporal y vocal, entrelazando la interpretación actoral con las canciones y danzas, tornándose un espacio por excelencia de fabricación de estrellas. En ese contexto, el cine es el ámbito por excelencia de educación del cuerpo ámbito de libre acceso a las mujeres que impulsa la convivencia social y la moda, la identificación de nuevas ideas y la elevación, no sin resistencias y críticas, de ídolos, pertenecientes a los llamados sectores populares.

La cultura del tango constituye en Argentina una categoría de análisis estética que establece un sistema de representación social colectivo ${ }^{4}$ (CHARTIER, 1992, p. 56; MAUSS, 1969, p. 13-89). Coloca en la escena pública la relación de aproximación entre varones y mujeres a través del abrazo de tango. El tango llega rápidamente al cine en 1906 cuando Eugenio Py filma entre sus actualidades Tango Criollo en las arenas del Teatro San Martin; un modesto antecedente del musical a la argentina (CANETO, 1996, p. 84-85) que fue exhibido en diversas capitales del mundo. El discurso corporal del tango (danza) funcionó como una respuesta social a esa crisis; en palabras de Michel Foucault,

$4 \mathrm{El}$ origen prostibulario del tango fue desmentido por las investigaciones de Lamas y Binda (1998) quienes abordaron la complejidad del processo considerando el tipo, el tratamento y las ideologias de las fuentes históricas; la estratégia en esa investigación fue retomar las críticas para extraer informacion importantíssima sobre lo que ellos denominan la condición "multiclase" del tango. Según los investigadores, la mayoria de las crónicas de la primera década del siglo $\mathrm{XX}$, representa apenas la mirada de la oligarquia argentina que desconsidera la danza del tango, así como otras manifestaciones de la cultura popular. Como estilo definido de danza el tango se consolida entre 1880 y 1900; en el capítulo Registros de tango más antiguos verificados, Lamas y Bindas detectan tres referencias de la danza que remiten a estratos sociales heterogeneos; las representaciones coreográficas el circo criollo, las crônicas de la guerra contra el Paraguay y los registros de la prensa sobre bailes en pueblos de veraneo, en la província de Buenos Aires. En el Diario del 30 de enero de 1888 localizan la que fue, tardiamente la primera descripción del tango bailado. Ambos autores sostienen que el tango no era algo prohibido, pues encuentran innúmeros relatos sobre las academias de baile y las innovaciones coreográficas en las Milongas, donde se ejecutaban "[...] quebradas, medias lunas, corridas, zapateos y tendidos" (LAMAS; BINDA, 1998, p. 154). El teatro Politeama, por ejemplo, fue descripto en la prensa local como una "verdadera academia", pues sus bailarines realizaban "cortes y variaciones", expresiones del lenguaje musical que remiten a un clímax coreográfico de alta intensidad. 
estructuró un dispositivo de conexión corporal totalmente original que operó en pró de la creación artística. Como expresión de esas nuevas sensibilidades los tangos-milongas transitaron un camino desde las arenas del circo criollo, pasando por el drama gauchesco, el folletín, llegando a los teatros con Cabaret (formato que les otorgó lugar específico en la noche porteña a las orquestas y a los bailarines) y al cine. Ese tránsito desencadenó un intenso proceso de transmisión y de codificación gestual asociado al género, puesto que la danza, la canción y la actuación de mujeres no fue una mera transposición de la técnica masculina, sino un diálogo, en que ambos participaron en la construcción de las relaciones de poder en esos nuevos terrenos de creación.

Las mises-en-scène coreográficas también reflejaron los nuevos lazos sociales creados a partir de la inmigración. Un análisis estructural de la primera filmografía nos muestra que el cuerpo se presenta en espacio fílmico dentro de un entramado de diversas camadas; performances on stage cuando los directores recrean coreografías en escenas de shows o cabarets, off stage, destacando las relaciones de género en escenas de milonga o los bailes de los conventillos y back stage cuando dentro de la diegesis fílmica los movimientos forman parte de espacios de transmisión, porque se enseña a bailar, se ensaya o se reflexiona sobre los códigos del baile (HANNA, 1988). El cuerpo y la sensibilidad de las mujeres compartían la escena fílmica presentando el cuerpo como el mapa de ese encuentro que es el tango como danza.

Las manifestaciones musicales y coreográficas del tango fueron adoptadas y estimuladas por el proyecto político de la clase dirigente y, llegado 1910, obtuvieron notabilidad durante las conmemoraciones del Centenario. En este contexto, la representación del gaucho y la expresión corporal del tango comenzaron a estar al servicio del modelo nacionalizador. Y si bien eso catapultó socialmente al tango, la visión de los directores de cine fue más allá del mero utilitarismo de su lenguaje. Por su estación social (inmigrantes en su mayoría) productores, escritores, directores, se sentían verdaderamente identificados con esa poética gestual y ese formato multicultural del tango entendido como una verdadera filosofía popular.

Directores como Agustín J. Ferreyra, Enrique Sussini, Manuel Romero y Mario Soffici, desarrollaron una forma cinematográfica cuyo lenguaje imaginético vinculaba el cine a personajes del tango que aprovechaba para representar la trama del mundo porteño. La filmografía de Ferreyra diseñó una especie de poema cinematográfico del tango, asociando lugares, personajes y situaciones al proceso de creación de un imaginario colectivo (COUSELO, 1977, p. 1298). Retomada y continuada por otros directores, esa poética creó un registro visual con sustento testimonial de técnicas corporales que expresaban la sensibilidad popular. El cine silente fue uno de los mayores espacios de transmisión de la 
danza y de los códigos corporales femeninos en una sociedad que aún sobrevaloriza la reclusión de la mujer como un bien moral.

Pioneras como Camila Quiroga, Azucena Maizani y Tita Merello, entre otras, tuvieron la visión de producir significados activando técnicas corporales en actuación, danza y estilos vocales inéditos. El trabajo sobre el cuerpo y la voz fue desarrollado con gran inteligencia creativa dentro del mercado artístico gracias al espíritu de lucha que marcó las críticas y los reveses de sus carreras.

\section{Resistencias y las tecnologías de género}

Si es cierto que muchas mujeres argentinas ocupaban una región marginal (DOS SANTOS, p. 2223), algunas consiguieron producir espacios nuevos de intervención social conjugando danza, interpretación, composición dentro de ese mundo manejado casi exclusivamente por hombres. Dos Santos presenta la realidad de esas mujeres atraídas por formarse en las artes del espectáculo como trabajadoras solitarias de su cuerpo y de sus voces, principalmente en las clases más bajas.

A fines del siglo XIX y comienzos del XX, gracias también a la popularización del fonógrafo, algunas mujeres trabajaron en academias cobrando por pieza de baile. Algunas siguieron el oficio del piano que era solo masculino fuera de casa y las tornó compositoras puertas adentro. Pero las más dotadas para la actuación y el canto, como lo eran las cupletistas ${ }^{5}$, tonadilleras o estilistas (cantantes de Zarzuelas) comenzaron a generar un espacio de reconocimiento público (DOS SANTOS, 1994, p. 2237-9). En 1917, con el nacimiento del tango canción, se abrió un mundo nuevo para las actrices que se atrevieron a cantar tangos. Se advierte un proceso de investigación vocal que configuró el movimiento de las llamadas "cancionistas" y cuyo producto estético se define a partir de 1930.

Una figura siempre relegada de ese período fue la actriz y productora cinematográfica Camila Quiroga ${ }^{6}$, entrerriana que llega a Buenos Aires, se inicia en el teatro dramático y llega a participar de nueve filmes 7

5 Fueron cupletistas antes de compositoras y cantantes de tango Pepita Avellaneda, Rosita Quiroga, Linda Thelma y la gran actriz Lola Membribes.

6 Camila Josefa Ramona Passera (1891-1948)

7 En el período silencioso actúa en ficciones como Mariano Moreno y la revolución de Mayo (Garcia Velloso, 1915), Resaca (Lipizzi, 1916) ¿Hasta dónde? (Quiroga, 1917) Juan Sin Ropa (Benoit, 1919); y, con la llegada del sonoro, en Viento Norte (Soffici, 1937) y Veinte años y una noche Zavalia, 1941). 
FIGURA 1 - CAMILA QUIROGA INTERPRETA HAMLET, BUENOS AIRES

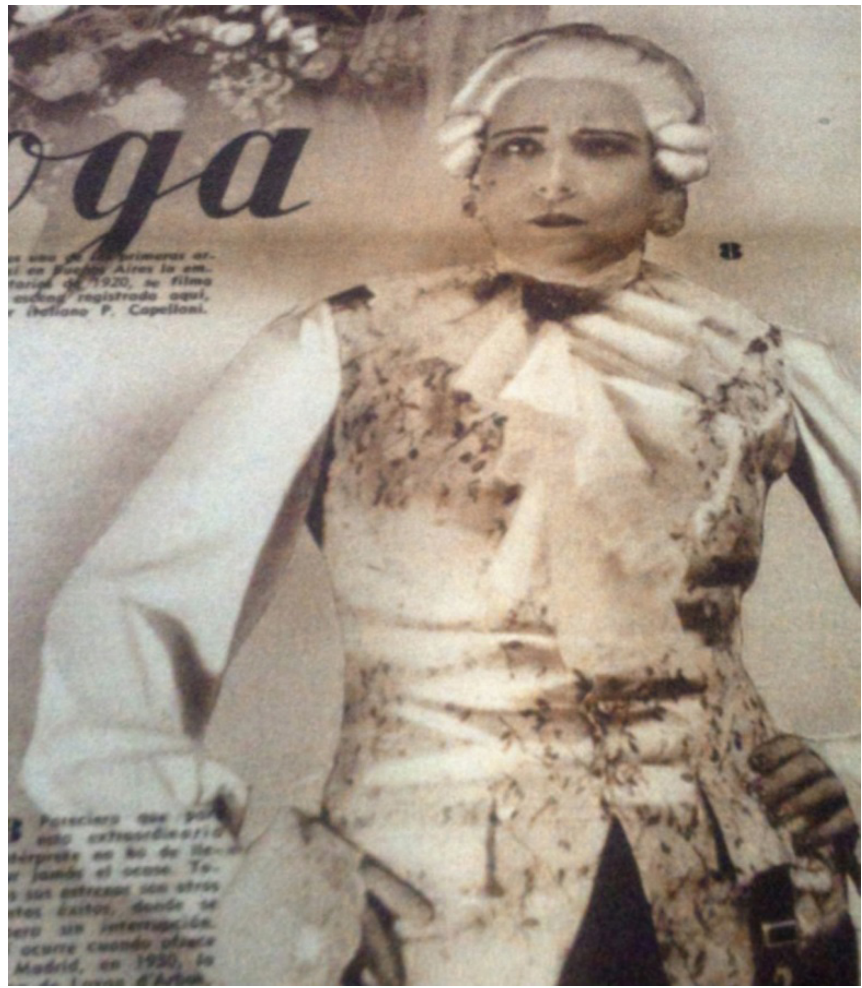

FUENTE: Archivo Fondo Nacional Jacobo De Diego, Archivo I.N.E.T.

Según García, hay una suerte de vacancia en lo que respecta a la dimensión social y política en la historiografía ${ }^{8}$ sobre Camila Quiroga; considerando que fue una actriz consagrada en 1917 en la Argentina, e internacionalmente reconocida en los años sucesivos (GARCIA, 2016). Quiroga va construyendo su camino en dirección hacia papeles protagónicos y trabaja con Pablo Podestá, Elías Alippi, entre otros que también hicieron ese salto del teatro al cine.

8 Su labor acompañó momentos turbulentos del país como la Semana Trágica en 1919, y los cambios en las formas de producción artísticas, tanto en el teatro como en el cine. Su formación artística se da dentro de un período de pasaje clave del poder de las manos de la élite conservadora y terrateniente para el sufragio secreto, obligatorio y universal con la ley Sáenz Peña de 1912, que logrará posicionar a Hipólito Yrigoyen como presidente. Un segundo momento durante la presidencia de Marcelo T. de Alvear (1922-1928), gobierno que culminaría con el comienzo de la "década infame" a fuerza del golpe de estado de 1930. 
Camila Quiroga aborda papeles en obras de teatro que apuntan cuestiones de género, abuso, violencia e injusticia social, siempre dentro de un realismo naturalista. Su actuación habría opacado al propio Pablo Podestá al utilizar procedimientos populares que irrumpían frente al público con una dicción interpretativa intensa, como bajar el volumen de la voz para mostrar angustia, o realizar pausas marcantes, que excedían lo declamatorio dentro de los cánones de la época (PELLETTIERI, 2009, p.7 apud GARCIA, 2016).

En el ámbito teatral de Buenos Aires, a principio del siglo XX, había una fuerte división entre dos tipos de actores/actrices, "nacional" o cómico y "dramático" o "culto", diferenciándose también la extracción socio cultural del público. En el primer caso era público proveniente de sectores populares y en el segundo, atraía a la burguesía media y alta. Y por fuera de ese esquema bipartito encontramos los espectáculos de variedades y Cabarets que moldearon en parte los primeros sucesos del cine sonoro asociados al canto y la danza. En el circuito teatral, la actuación de Quiroga fue catalogada de dramática y obtuvo gran reconocimiento nacional e internacional por sus cualidades interpretativas, su voz, elegancia y sentimiento. En 1919 produce con su marido y actúa en Juan sin ropa (BENOIT; QUIROGA, 1919) representando los primeros levantamientos populares de obreros y las relaciones de sumisión que se establecían con la industrialización en la ciudad y el campo argentino.

En la Enciclopedia de Teatro de Nueva York correspondiente a los años 1920-1930 la Compañía de Camila Quiroga y ella, como directora, es mencionada varias veces; a pesar de su repercusión como actriz dramática en Argentina, la Enciclopedia refiere a las críticas del Times en que sorprenden afirmando que su trabajo era una extraña mezcla de vaudeville con melodrama (LEITER; HILL, 1985, p. 295). Por otro lado, durante su pasaje por México, donde el teatro se hacía aún con el español de España, Quiroga también imprime en su forma de hablar el acento argentino en un gesto de libertad que fue muy elogiado.

Después de un período de giras teatrales Camila Quiroga participa en Argentina de Viento Norte (SOFFICI, 1937), gran éxito cinematográfico de Argentina Sono Film. El tema elegido por Soffici en colaboración con Vacarezza retomaba libremente la obra de Lucio V. Mansilla sobre la expedición a los indios Ranqueles; tema y tratamiento iban contra la corriente, si se considera el tipo de producción popular que la productora de Ángel Mentasti buscaba, eligiendo actores provenientes de la revista o la radio. Mentasti aprovecha los nombres famosos de Muiño, Alippi y Quiroga para realizar acuerdos de venta, antes de iniciar el proprio rodaje.

La película Viento Norte se estrena en octubre de 1937 en el Cine Monumental, con una platea llena, constituida por 1830 butacas. Y Quiroga recibió ciertas críticas, por ejemplo, de Di Nubila quien destacó la gran calidad de las 
interpretaciones de Enrique Muiño, Elías Alippi y Ángel Magaña, en detrimento de Camila Quiroga, que sobreactuó el papel sin adaptarse a la contención del trabajo ante las cámaras (DI NUBILA, 1959, p. 94). En contrapartida, la prensa hizo alusión al peso dramático de Quiroga que, si bien denotaba teatralidad, también emocionaba al espectador (EL HERALDO, 20/10/1937), fundamentalmente en las partes finales (LA PRENSA, 14/10/1937). La difícil tarea de agradar a la crítica dentro de esa estructura teatral bipolar en que se extendía al cine ${ }^{9}$ tornó a Camila Quiroga una actriz que no fue, según García, ni dócil ni nacional; una mujer que supo aprovechar, tal vez más fuera del país, el lenguaje corporal de actuación asociado a las formas de teatro popular rioplatense. Su talento en el arte de la gestualidad le permitió acceder al éxito con libertad y aprovechar la efusividad del teatro criollo y de su formación dramática cuando los precisó.

Otra mujer destacada fue Azucena Maizani (1902-1970), compositora, cantante, productora teatral y actriz de gran éxito nacional e internacional. $\mathrm{Su}$ carrera se extendió de 1919 a 1947. Trabajó como costurera y participó de un coro hasta estrenar, a sus 17 años, como corista desconocida en El bailarín del cabaret, obra protagonizada por el famosísimo Ignacio Corsini y Eva Franco. Un año después, canta en una fiesta familiar con su característica voz grave frente a Enrique Delfino, quien se impresiona y la presenta al empresario teatral Pascual Carcabello. Su debut en el Teatro Nacional fue en 1923 cantando el tango Padre Nuestro en el sainete $A$ mí no me hablen de penas del dramaturgo Alberto Vacarezza. El público le hizo repetir cinco veces el bis. El trabajo de cinco arduos años la transformó en una estrella de teatro, radio y, en 1929, de cine. Con su corte de cabello a la garçon fue convocada para estrenar diversos tangos ${ }^{10}$, muchos de ellos introducían la mirada de la mujer de la época, sobre moda, cabello o el proprio tratamiento en relación con los hombres; como en la letra de Cascabelito (BOHR), en que se describe la pasión de los hombres por un tipo nuevo de mujer, esa que, durante el carnaval, besa y huye sin culpa, escondida tras la máscara festiva.

9 Y según la crítica de Caras y Caretas:Si no fuera que el Viento Norte no se descubre más que en una desorbitada expresión de Orestes Caviglia; si no fuera que Camila Quiroga gime y llora tan insuperablemente como jamás lo hizo en sus gemebundas y lacrimosas interpretaciones de su ya larga carrera teatral; y, finalmente si no fuera por algunos defectos de sonido y otras cosas más, este film dirigido por Soffici con argumento de Vacarezza, se clasificaría entre los pocos buenos que nuestra cinematografía ha presentado (Caras y Caretas, 30/10/1937, p. 35).

10 Maizani estrena tangos como Silbando, Organito de la tarde, Pato, Amigazo y Esta noche me emborracho. Canta para la orquesta de Francisco Canaro y recibe el seudónimo de $\mathrm{La}$ ñata gaucha de su amiga Libertad Lamarque que refiere a ese tono compadre de Maizani. Su carrera estuvo marcada por innúmeras giras al interior del pais en el comienzo y luego a Montevideo; pero después de 1928 viaja a América del Norte, España y Portugal. Maizani grabó 270 discos en toda sua vida artística. 


\section{FIGURA 2 - AZUCENA MAIZANI CON VESTUARIO TEATRAL MASCULINO}

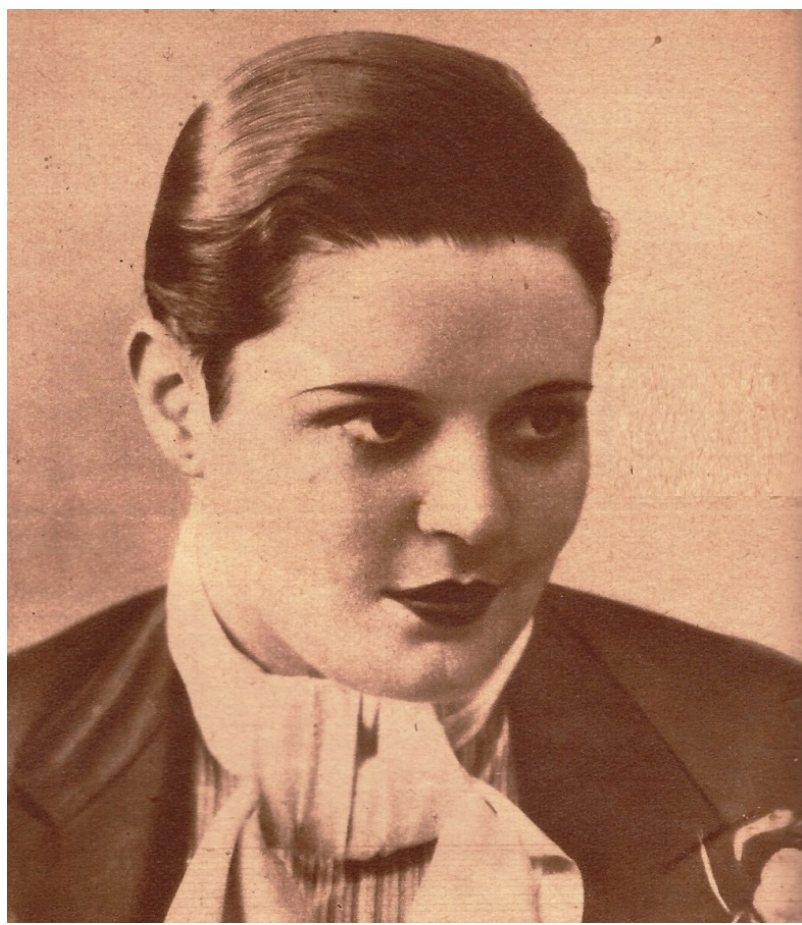

FUENTE: Revista Cine Argentino, n 73, Buenos Aires, 1939.

Azucena Maizani se consolida como estrella en compañías de teatro como la de Elías Alippi y forma su propia compañía, a través de un trabajo personal asociado a la interpretación argumental de las canciones. Su performance crea el formato de la actriz de tango. Había un gran interés por lograr el reconocimiento al punto de dejar un empleo fijo en el teatro y trabajar por hora en espectáculos que realizaba durante los "finales de fiesta" de las proyecciones cinematográficas y que, a veces, se repetían en la misma jornada. Según la propia Maizani, fue allí donde pudo apreciar cómo su nombre había ingresado en las masas populares, que le daban claras pruebas de aceptación de su labor (MAIZANI Apud CLIFFORD, 1939).

En el cine silente actúa bajo la dirección de Julio Irigoyen en La casa del placer (1929) pero su verdadero éxito está ligado a la primera película con sonido óptico realizada y estrenada comercialmente en Argentina: Tango! de Moglia Barth (1933). Maizani canta un tema de su autoría en la abertura del filme La canción de Buenos Aires entre otros como Botines viejos. Actuó en 
Monte criollo (MOM, 1935) y Nativa (ROSAS, 1939); su última película fue Buenos Aires Canta (1947) de Antonio Solano. Participando con nombre propio en las películas, Maizani fue considerada la mayor cancionista del tango, siempre mantuvo un perfil extremamente profesional; cuando otras estrellas nacieron, a partir de los años de 1940, continuó actuando, a pesar de tener que reducir sus actuaciones a locales más populares. Como trabajadora de la cultura sólo abandonó su carrera tras una hemiplejia en 1966.

La historia audiovisual de las mujeres en Argentina coloca en perspectiva los marcadores formales, temáticos y estilísticos tras la performance on stage de la mujer en escena; su visión de la realidad, los usos del cuerpo descentrados de la tradición masculina y los procesos de autopoiesis en la ocupación de nuevos espacios de producción enfatizan procesos estéticos subjetivos que trascienden del hogar a lo social a través de la mediatización acústica y visual del cuerpo y la voz. Ciertamente, las historias de la radio y del cine argentino no han otorgado aún la merecida atención a estos procesos formativos artísticos y de educación del cuerpo; siendo que, son estos procesos los que resignifican toda nuestra comprensión acerca de las políticas de representación, de lo visible y de lo audible en las primeras décadas del siglo XX.

\section{REFERENCIAS}

ARCHETTI, E. O gaúcho, o tango, primitivismo e poder na formação da identidade nacional argentina. Mana - Revista de Estudos de Antropologia Social, Rio de Janeiro, v. 9, n. 1, p. 9-29, 2003.

AYERSA, F. Escenas del campo argentino (1885-1900). Buenos Aires: Academia Nacional de Bellas Artes, 1968.

BARRANCO, D. Historia, historiografía y género. Notas para la memoria de sus vínculos en la argentina. Revista La Aljaba, Buenos Aires, v. 9, p. 49-52, 2004-2005.

CANETO, G. Historia de los primeros años del cine en La Argentina (1895-1910). Buenos Aires: Fundación Cinemateca Argentina, 1996.

CHARTIER, R. El mundo como representación. In: CHARTIER, R. Historia cultural: entre práctica y representación. Barcelona: Gedisa, 1992.

CLIFFORD, C. La vida artística de Azucena Maizani. Revista Cine Argentino, n. 73, Buenos Aires, 1939.

COUSELO, J. M. El tango en el cine. In: ALPOSTA, L.; ORDAZ, L.; COUSELO, J.M. La historia del tango VIII: El tango en el espectáculo I. Los bailes del internado, el teatro, el cine. Buenos Aires: Corregidor, 1977. p. 1190-1328. 
CUARTEROLO, A. De la foto al fotograma. Relaciones entre cine y fotografía en la Argentina (1840- 1933). Montevideo: CDF Ediciones, 2006.

DE LAURETIS, T. Technologies of Gender. Essays on Theory, Film, and Fiction, Bloomington: Indiana University Press, 1987.

DI NUBILA, D. Historia del Cine Argentino. Vol I. Buenos Aires: Cruz de Malta, 1959.

DOS SANTOS, E. Las cantantes. In: DOS SANTOS, E. La historia del tango. Vol. 13. Buenos Aires, Corregidor, 1994.

FUMAGALLI, A. Historia del Ballet en Argentina. Revista Son del Sur, Buenos Aires, 24 julio, 2014.

GARCIA, E. S. Camila Quiroga, voz de mujer. Legitimación de la voz femenina en la poética de actuación de Camila Quiroga. In: CONGRESO INTERNACIONAL ARTES EN CRUCE, 4., 2016. Anais... Facultad de Filosofía y Letras/IIEGE, Universidad de Buenos Aires. Buenos Aires, 2016.

GIL LOZANO, F.; PITA, V. S.; INI, G. M. Historia de las mujeres. Vol 1. Buenos Aires: Alfaguara, 2000.

HANNA, J. Dance, Sex and Gender. Sings of identity, dominance, defiance and desire. Londres: Editora, University of Chicago Press, 1988.

KARUSH, M. Cultura de clase. Radio y cine en la creación de una Argentina dividida (1920-1946). Buenos Aires: Ariel, 2013.

LAMAS, H.; BINDA, E. El tango en la sociedad porteña 1880-1920. Unquillo: Abrazos, 1998.

LEITER, L.; HILL, H. The Encyclopedia of the New York Stage, 1920-1930 (12/8/27) New York: Greenwood Press, 1985. p. 295-296.

MAUSS, M. Oeuvres 2. Representations collectives et Diversité des Civilisations. Paris: Minuit, 1969. p. 13-84.

MAUSS, M. As técnicas corporais. In: MAUSS, M. Sociologia e Antropologia. São Paulo: EDUSP, 1974. p. 209-233.

MAUSS, M. Sociología y antropologia. Madrid: Tecnos, 1979.

PELLETTIERI, O. Camila Quiroga: entre el drama y la naturalidad. Revista del Getea, Buenos Aires, Teatro XXI, n. 27, 2009.

SOARES, C. Corpo e História. Campinas, São Paulo: Autores Associados, 2006.

SOARES, C. L. Educação do corpo. In: GONZALEZ, F. J.; FENSTERSEIFER, P. E. Dicionário de Educação Física. 3. ed. Ijuí: Umnat, 2014.

Texto recibido el 27 de marzo de 2018. Texto aprobado el 18 de mayo de 2018. 